\title{
Cognitive interpersonal maintenance model of eating disorders: intervention for carers
}

Elizabeth Goddard, Pamela Macdonald, Ana Rosa Sepulveda, Ulrike Naumann, Sabine Landau, Ulrike Schmidt and Janet Treasure

\section{Background}

Carers of people with eating disorders report high levels of distress. In addition, carers' responses to the illness may perpetuate eating disorder symptoms. A cognitive interpersonal maintenance model of eating disorders is proposed and interventions for carers may improve wellbeing in both carers and patients.

\section{Aims}

To examine an interpersonal maintenance model of eating disorders, using a self-help intervention for carers.

\section{Method}

A pre-test-post-test design was used with carers randomised into self-help or guided self-help, which included the Expert Carers Helping Others (ECHO) intervention. Carers' distress, well-being, proposed maintenance factors, and carer reports on the status of the patient were measured.

\section{Results}

Carers' distress reduced and secondary outcomes improved. Improvement in carers' status and perceived improvements in patients were associated with reductions in expressed emotion and in accommodating and enabling behaviours. self-help and guided self-help versions were comparable.

\section{Conclusions}

Changes in maintenance factors from the theoretical model were associated with a reduction in carers' distress and improvement in perceived patient functioning. Interventions which specifically target maintaining factors may be of benefit.

\section{Declaration of interest}

J.T. is co-author of the book used in the ECHO intervention and was part of the team who developed the DVDS. P.M. was one of the telephone coaches in the project.
Empirical testing is essential for rigorous complex intervention evaluation and for further refinement of the underpinning theoretical framework. ${ }^{1,2}$ The cognitive interpersonal maintenance model of eating disorders ${ }^{3}$ provides a theoretical basis for carer interventions. Carers' expressed emotion ${ }^{4}$ (e.g. emotional overinvolvement, criticism and hostility) and enabling and accommodating behaviours ${ }^{5,6}$ are proposed to maintain the illness. The model, which can be applied trans-diagnostically, describes a causal chain whereby high levels of carer unmet needs ${ }^{7-9}$ and a reduced ability to cope contribute to carers' high expressed emotion and ineffective strategies in managing symptoms. These responses cause distress in carers ${ }^{10,11}$ and allow eating disorder symptoms to flourish. Expert Carers Helping Others (ECHO), a self-help intervention for carers, targets these proposed interpersonal maintaining factors. Expert Carers Helping Others can be supplemented with telephone coaching sessions using the principles of motivational interviewing, a client-centred therapeutic tool employed to elicit behaviour change. ${ }^{12}$ Preliminary studies found that the intervention improved carer well-being. ${ }^{13,14}$

Hypotheses to be tested in this study were:

(a) ECHO will reduce the level of carer distress;

(b) ECHO will produce positive changes in secondary outcomes of caregiving self-efficacy and burden, well-being, expressed emotion, accommodation and enabling behaviour;

(c) at post-intervention, carers will report an increase in level of functioning in the individuals with an eating disorder for whom they care:

(d) changes in maintaining factors (expressed emotion, self-efficacy, accommodating and enabling) will mediate intervention effects on carer distress and perceived eating disorder symptoms;

(e) ECHO will have a greater effect on those for whom the intervention is most relevant (i.e. those with high levels of expressed emotion and accommodating and enabling behaviour, low levels of self-efficacy); it is also predicted that living situation, amount of face-to-face contact, and duration of illness will moderate the intervention effect;

(f) telephone coaching using motivational interviewing will enhance effects of ECHO.

\section{Method}

\section{Participants}

Participants were a community sample of carers recruited from the UK between September 2006 and February 2009. The definition of 'carer' used is that of the Princess Royal Trust for Carers (UK Charity) (www.carers.org) and includes partners, siblings and other relatives or friends who provide unpaid help and support. Inclusion criteria required individuals to be fluent in English. Written informed consent was obtained for all participants.

Ethical approval was from King's College London. Recruitment was conducted via posters and fliers in clinics and on our website, www.eatingresearch.com.

\section{Design and procedure}

All carers were first assessed once consent had been obtained (baseline time point), at which point they waited for 6 weeks ( $n=119)$ (matching the 6-week duration of the intervention) before they were assessed for a second time (pre-intervention time point). The waiting period allowed us to examine the stability of the caregiving experience over a time period equivalent to the intervention period. Owing to limited resources, this waiting period was reduced to 2 weeks for a final subset of participants $(n=34)$. After the second assessment, carers were randomised to receive self-help only (ECHO) or guided self-help (ECHOc). 
Post-intervention assessment data were collected at 6 weeks (postintervention time point) and at 3 months post-intervention (follow-up time point). All assessments were collected by postal questionnaires; consequently, assessor masking was not necessary.

\section{Intervention}

All carers received written material (a book) ${ }^{15}$ and five DVDs (three theoretical; two practical skills) via the post after the second assessment.

Both $\mathrm{ECHO}$ and $\mathrm{ECHOc}$ include many behaviour change strategies defined according to the published taxonomy, ${ }^{16}$ including: providing information on the behaviour-health link; identification of barriers to change; general encouragement; graded tasks; behavioural goals and contracts; modelling; prompts and cues; self-talk; and stress management skills.

Carers allocated to ECHOc received an additional three telephone coaching sessions approximately $40 \mathrm{~min}$ in duration (plus an introductory telephone call lasting $15-20 \mathrm{~min}$ ). The majority of sessions were delivered by two coaches (a nonprofessional who had been a carer herself and a senior clinical nurse who specialised in eating disorders). The third coach was a clinical psychologist. The coaches were trained in motivational interviewing ${ }^{17}$ and used this to target the behaviour change goals in ECHO. Weekly supervision was available.

\section{Measures}

The primary outcome (carer distress) and key factors within the maintenance model, i.e. expressed emotion and level of functioning of the individual with the eating disorder (reported by carer) were measured at four time points: baseline, preintervention, post-intervention, and 3-month follow-up. Assessments for other secondary outcomes were collected at baseline, pre- and post-intervention (not follow-up).

1 Hospital Anxiety and Depression Scale (HADS) $)^{18}$ is a 14 -item self-report measure assessing presence and severity of anxiety and depression over the previous week. Scores are calculated on a 4-point Likert scale. The scale shows high internal reliability in this sample ( $\alpha=0.9$ across time points).

2 The General Health Questionnaire $(\mathrm{GHQ})^{19}$ is a 12 -item measure assessing general well-being over the previous few weeks using a 4 -point Likert scale $(\alpha=0.9)$.

3 The Experience of Caregiving Inventory $(\mathrm{ECI})^{20}$ is a 66 -item measure that assesses levels of caregiving burden in carers. Items explore both positive and negative aspects of caring using a 5-point Likert scale $(\alpha=0.7-0.9)$.

4 The Eating Disorder Symptom Impact Scale (EDSIS) ${ }^{21}$ is a 24-item scale that measures caregiving burden related to symptoms specific to the eating disorder using a 5-point Likert scale $(\alpha=0.9)$.

5 The Family Questionnaire $(\mathrm{FQ})^{22}$ is a 20 -item self-report measure exploring levels of expressed emotion in carers. Scores are given on a 4 -point Likert scale $(\alpha=0.8-0.9)$.

6 The Revised Scale for Caregiving Self-Efficacy $(\mathrm{CSE})^{23}$ is a 15item self-report measure that measures caregiving self-efficacy. Scores are marked on a Likert scale ranging from 1 through to 100 in increments of $10(\alpha=0.8-0.9)$.

7 The Accommodation and Enabling Scale for Eating Disorders $(\mathrm{AESED})^{5}$ is a 33 -item self-report measure using a 5-point Likert scale assessing caregiver behaviours that may serve to accommodate the eating disorder $(\alpha=0.9)$.
8 Global Eating Disorder Functioning (GEDF). Adapted for carers from the Global Assessment of Functioning scale. ${ }^{24}$ Carers are asked to assess the general behavioural functioning of their loved one on a hypothetical continuum of ten equalpoint intervals (range 1-100, where 100 is the least impaired).

9 Eating Behaviours (EatBeh). Carers were asked to mark which behaviours they could identify in their loved one at that time: severely underweight, restricting food intake, exercising excessively, vomiting after meals, missing menstrual periods for 3 months or more, eating unusually large amounts of food in one sitting (binge eating), eating in secret, stealing food/money in order to binge, severely overweight or other behaviours. A variable was calculated to reflect the number of eating behaviours that an individual presented by summing the number of items endorsed.

10 Acceptability of intervention. Carers were asked to rate the proportion of DVDs watched on a visual analogue scale $(0=$ none, $10=$ all $)$ and how helpful they found the intervention for key areas (communication with their loved one, reactions to the eating disorder, own stress levels) (score $0-10)$.

\section{Sample size}

In a pilot study (self-help only), we found a change in carer distress between pre- and post-ECHO intervention corresponding to an effect size of 0.26 . To detect this difference with $80 \%$ power using a paired-samples $t$-test at a 0.05 significance level we estimated that a sample of $n=119$ would be needed. Therefore, we aimed to recruit 143 carers to account for a drop-out rate of $20 \%$.

\section{Randomisation}

Randomisation was conducted by a member of the research team, masked to the algorithm, using a random number generator List Randomiser that can be found on www.random.org. Carers were randomised in groups of four to five individuals using block randomisation. Group allocations were kept on a password protected secure electronic database and each carer was marked according to allocation. Carers were informed of group allocation by post.

\section{Statistical analysis}

The main analysis assessed the effect of ECHO on the primary outcome: carers' anxiety and depression (HADS). The secondary outcomes were observed patient measures of the global level of functioning and eating behaviours, both reported by the carer (GEDF and EatBeh), expressed emotion (FQ), well-being (GHQ), caregiving burden (ECI and EDSIS), accommodation and enabling of symptoms (AESED) and caregiving self-efficacy (CSE) of the carer. Only one carer per family was included in the analysis.

A linear mixed model was used to look for any significant changes in outcome scores from pre-intervention to postintervention with or without coaching. The outcome data at pre- and post-intervention formed the dependent variable. The independent variables are 'baseline data', a 'time' variable and a 'coaching' variable. The time variable takes the value of 0 at pre-intervention and 1 for scores at post-intervention. The coaching variable takes the value of 1 at post-intervention for the coaching group and 0 otherwise. Therefore, the time variable represents the effect of $\mathrm{ECHO}$, that is, the difference in outcome between pre- and post-intervention time points for those receiving ECHO. The coaching variable measures any incremental effect due 
to coaching. Random intercepts for individuals were included in the model to take account of the variance in the data that is due to individual differences. The model assumes that change between pre- and post-intervention can be attributed to the intervention and not to any other temporally varying variable.

\section{Variables with an additional follow-up time point}

The model was extended for outcomes available at 3-month follow-up (HADS, FQ and GEDF) and the dependent variable was then formed of the outcomes at pre-, post-intervention, and 3-month follow-up. An additional explanatory variable to explain the changes between post-intervention and follow-up in the ECHO group, and another covariate to explain the potential additional benefit in the ECHOc group at follow-up were added.

The number of missing values in our data varied for different outcomes. Therefore, for each outcome, we separately display the number of individuals with measurements and the total number of observations in the following results section. Observations for some individuals are not available for all time points. We assume that any missing data are missing at random. We fitted the mixed models using the maximum likelihood method, which provides estimates that are valid under the missing-at-random assumption.

Exploratory moderation and mediation analysis of the change over the intervention period

To assess whether the change in outcome between pre- and postintervention times depended on variables at pre-intervention, we extended the linear mixed model described above (excluding the follow-up time point) to contain a main effect of the hypothesised moderating variable at pre-intervention, an interaction of time and moderator variable and an interaction for coaching and moderator variable. The existence of moderating effects can be assessed by looking at the estimated interactions.

We referred to the criteria outlined by Baron \& Kenny ${ }^{25}$ for our mediation analyses. We assumed the absence of unobserved confounders in our analysis. A variable is a partial mediator of the effect of intervention (time) on outcome, if time significantly accounts for variations in the mediator variable and, additionally, if variations in the mediator variable significantly account for variations in outcome. Furthermore, the relation between time and outcome is less strong when both the mediator and time are included in the model, as the mediator explains part of the relationship between the other two variables.

Analyses were carried out in Stata 10 for Windows.

\section{Results}

The flow of participants is shown in the CONSORT diagram (Fig. 1). A similar number of participants in both intervention arms failed to complete the post-intervention and follow-up assessments.

\section{Clinical and demographic data}

Clinical and demographic features in ECHO and ECHOc at the second assessment are shown in Table 1. Table 2 displays

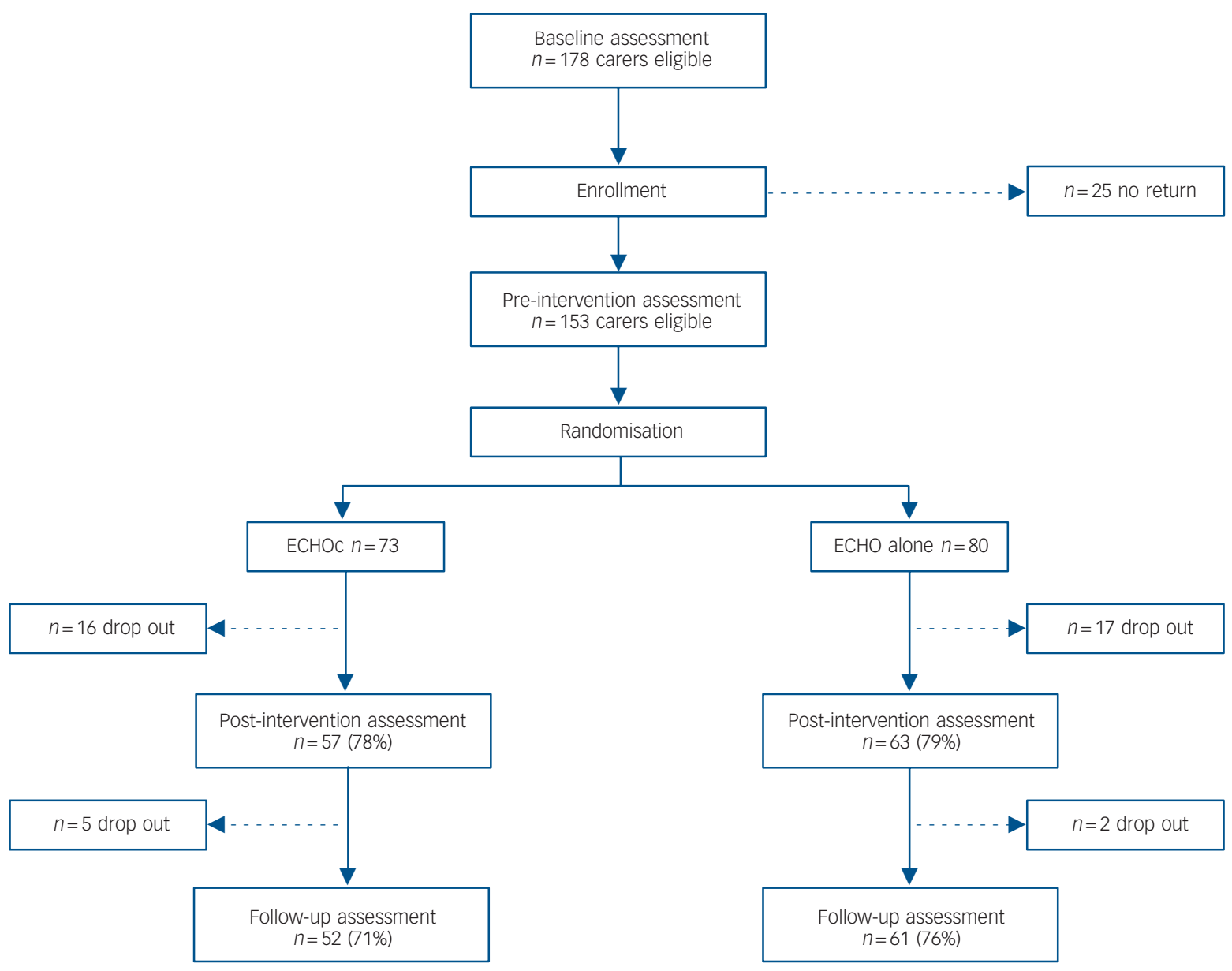

Fig. 1 Consort diagram depicting participant flow through study. 


\begin{tabular}{|c|c|c|}
\hline Demographic & $\begin{array}{l}\mathrm{ECHO} \\
(n=80)\end{array}$ & $\begin{array}{l}\mathrm{ECHOC} \\
(n=73)\end{array}$ \\
\hline Carer's age, years: mean (s.d.) & $50.5(6.9)$ & $48.7(9.1)$ \\
\hline Carer's gender, n: F:M & $74: 6$ & $62: 11$ \\
\hline $\begin{array}{l}\text { Carer's employment status, } n \\
\text { Full/part time } \\
\text { Unemployed/retired/housewife/-husband } \\
\text { Sick leave }\end{array}$ & $\begin{array}{r}59 \\
14 \\
2 \\
\end{array}$ & $\begin{array}{r}47 \\
17 \\
7\end{array}$ \\
\hline $\begin{array}{l}\text { Carers' marital status, } n \\
\text { Married/living together/civil partner } \\
\text { Divorced/separated/widowed } \\
\text { Single }\end{array}$ & $\begin{array}{r}61 \\
16 \\
3\end{array}$ & $\begin{array}{r}66 \\
6 \\
1\end{array}$ \\
\hline $\begin{array}{l}\text { Relationship to patient, } n \\
\text { Parent, mother:father } \\
\text { Spouse/partner } \\
\text { Child } \\
\text { Other (e.g. friend, aunt, sibling) }\end{array}$ & $\begin{array}{c}72: 3 \\
3 \\
0 \\
2\end{array}$ & $\begin{array}{c}58: 6 \\
5 \\
2 \\
2\end{array}$ \\
\hline Patient's gender, $n: F: M$ & $76: 4$ & $70: 3$ \\
\hline Patient's age, years: mean (s.d.) & $20.8(6.9)$ & $20.9(6.8)$ \\
\hline $\begin{array}{l}\text { Patient's diagnosis, } n \\
\text { Anorexia nervosa } \\
\text { Bulimia nervosa } \\
\text { Eating disorder NOS }\end{array}$ & $\begin{array}{c}63 \\
7 \\
4(+2)^{b}\end{array}$ & $\begin{array}{c}59 \\
5 \\
1(+1)^{b} \\
\end{array}$ \\
\hline $\begin{array}{l}\text { Current treatment, } n \\
\text { In-patient/day patient } \\
\text { Out-patient } \\
\text { None }\end{array}$ & $\begin{array}{l}20 \\
42 \\
23\end{array}$ & $\begin{array}{l}13 \\
48 \\
16 \\
\end{array}$ \\
\hline $\begin{array}{l}\text { Duration of illness, years: } \\
\text { median (IQR) }\end{array}$ & $3(7)$ & $4(7)$ \\
\hline $\begin{array}{l}\text { Ever admitted to hospital, } n \\
\text { Yes } \\
\text { No }\end{array}$ & $\begin{array}{l}43 \\
35\end{array}$ & $\begin{array}{l}34 \\
38\end{array}$ \\
\hline
\end{tabular}

\begin{tabular}{|lcc|}
\hline No & 35 & 38 \\
\hline $\begin{array}{l}\text { Times admitted to hospital, } \\
\text { median (IQR) }\end{array}$ & $1(1)$ & $0(1)$ \\
\hline $\begin{array}{l}\text { Length of time spent in hospital, months: } \\
\text { median (IQR) }\end{array}$ & $1(15)$ & $0(8.3)$ \\
\hline $\begin{array}{l}\text { Length of time in past 6 months, weeks: } \\
\text { median (IQR) }\end{array}$ & $0(3.5)$ & $0(0.3)$ \\
\hline $\begin{array}{l}\text { Currently receiving family therapy, yes } \\
\text { Carer currently attending a carer support } \\
\text { group, yes }\end{array}$ & 24 & 19 \\
\hline $\begin{array}{l}\text { Currently living with relative, } n \\
\quad \text { Yes }\end{array}$ & 22 & 19 \\
$\quad$ No & 63 & 54 \\
\hline $\begin{array}{l}\text { Face-to-face contact, hours per week } \\
<21\end{array}$ & 15 & 16 \\
$\quad>21$ & 40 & 29 \\
\hline
\end{tabular}

Other contact (e.g. telephone),

hours per week

$\begin{array}{rrr}<21 & 63 & 55 \\ >21 & 1 & 6\end{array}$

ECHO, Expert Carers Helping Others self-help only intervention; ECHOC, Expert Carers Helping Others guided self-help intervention; NOS, not otherwise specified; IQR, interquartile range.

a. Not all questions were answered by all carers.

b. Carers did not feel confident to provide a diagnosis.

pre- and post-intervention values of primary and secondary outcomes. Change scores over the waiting period were calculated for HADS (mean -0.7 , s.d. $=5.9$ ), FQ (mean -0.5 , s.d. $=6.2$ ), AESED (mean -2.2 , s.d. $=13.6)$, EDSIS (mean -4.9, s.d.=11.1), CSE (mean 0.3, s.d.=13.5), GHQ (mean -0.9, s.d. $=5.7)$, ECI negative (mean -7.5 , s.d. $=22.6$ ), ECI positive $($ mean -0.9 , s.d. $=6.7)$, GEDF $($ mean 2.3, s.d. $=11.9)$ and EatBeh $($ mean -0.4 , s.d. $=1.1)$.

\section{Main effects}

The main effects of ECHO at the post-intervention time point are displayed in Table 3. There were no significant effects for coaching over and above intervention alone (except for GEDF and EatBeh, discussed below), therefore coaching effects are not shown. Analyses were conducted with and without the 34 people who received the 2-week waiting period (compared with the 6-week period) and the results were similar; therefore, data for the total sample are shown.

\section{Change in carer anxiety and depression over time}

The HADS score was reduced at post-intervention in both groups. The intervention effect was maintained at follow-up (estimated reduction: $-4.8, P<0.001 ; 95 \% \mathrm{CI}-6.3$ to -3.4$)$.

For total HADS scores, $33 \%$ of carers scored outside of range (two standard deviations from the norm mean) ${ }^{27}$ at pre-intervention, $22 \%$ scored outside of this range at postintervention, and $17 \%$ at 3 -month follow-up. These results, therefore, are of clinical significance for this population.

\section{Change in secondary outcomes}

Carers benefit from the intervention for almost all of the secondary outcomes. The FQ scores decreased significantly at post-intervention and decreased further at follow-up (estimated reduction at 3-month follow-up: $-4.3, P<0.001 ; 95 \%$ CI -6.2 to -2.4). The AESED scores were significantly reduced and CSE improved at post-intervention. Scores for GHQ, ECI and EDSIS also fell. There were no significant changes in positive aspects of ECI. Telephone coaching had no significant additional benefit on carer outcomes (FQ: $P=0.9$; GHQ: $P=0.3$; AESED: $P=0.2$; CSE: $P=0.5$; ECI negative: $P=0.9$; EDSIS: $P=0.3$; ECI positive: $P=0.1$ ).

Carers reported an increase in GEDF scores and this effect is further increased at 3-month follow-up (estimated increase 6.8, $P<0.001 ; 95 \%$ CI 3.8 to 9.8). Unexpectedly, this effect at follow-up was significantly greater in the standard ECHO group compared with the ECHOc group (estimated difference -5.7, $P=0.007 ; 95 \%$ CI -9.8 to -1.6 ). Also, carers in the ECHOc group reported a smaller reduction in EatBeh at post-intervention (estimated difference $0.6, P=0.01 ; 95 \%$ CI 0.1 to 1.0 ).

\section{Acceptability}

Descriptive data are presented in Table 4. Carers in the ECHOc group watched a greater proportion of the DVDs than carers in the ECHO group $(P=0.02)$. Carers in the ECHOc group also found the information more useful for the development of their communication skills $(P=0.04)$. Groups did not differ on other ratings.

\section{Exploratory mediation analyses}

Mediating role of improvements in proposed maintaining factors on carer distress

The intervention successfully reduced carers' HADS and also the factors thought to contribute to carer distress (i.e. FQ, AESED, CSE). Hence, we tested whether the intervention benefits carers' distress through its effects on proposed maintaining factors.

A model of anxiety and depression explained by the covariates, baseline HADS, time and coaching was compared with three models that additionally included the putative mediating variables. In each case, the estimated intervention effect lost significance on addition of the mediating variable. Change scores for FQ $(r=0.5, P<0.0001)$, AESED $(r=0.5, P<0.0001)$ and CSE 
Table 2 Pre- and post-intervention means for primary and secondary outcomes

\begin{tabular}{|c|c|c|c|c|}
\hline & \multicolumn{2}{|c|}{ ECHO, mean (s.d.) } & \multicolumn{2}{|c|}{ ECHOc, mean (s.d.) } \\
\hline & Pre-intervention & Post-intervention & Pre-intervention & Post-intervention \\
\hline Hospital Anxiety and Depression Scale & $18.9(9.0)$ & $15.6(8.7)$ & $19.0(8.1)$ & $15.1(7.2)$ \\
\hline Family Questionnaire & $51.5(9.5)$ & $48.8(10.2)$ & $50.8(9.3)$ & $47.4(9.9)$ \\
\hline Accommodation and Enabling Scale for Eating Disorders & $47.4(23.7)$ & $40.7(25.4)$ & $45.2(22.8)$ & $40.4(21.7)$ \\
\hline Eating Disorder Symptom Impact Scale & $37.7(18.1)$ & $32.6(17.3)$ & $40.1(18.6)$ & $33.3(19.1)$ \\
\hline Caregiving Self-Efficacy & $63.8(22.4)$ & $70.5(20.1)$ & $64.2(19.3)$ & $73.3(17.0)$ \\
\hline General Health Questionnaire & $17.5(7.1)$ & $15.0(7.4)$ & $18.7(7.6)$ & $14.5(5.9)$ \\
\hline Experience of Caregiving Inventory - negative & $95.2(38.3)$ & $81.0(39.2)$ & $96.3(39.4)$ & $81.3(32.6)$ \\
\hline Experience of Caregiving Inventory - positive & $28.7(6.9)$ & $29.7(8.7)$ & $27.0(8.9)$ & $30.2(9.6)$ \\
\hline Global Eating Disorder Functioning & $56.7(14.7)$ & $59.5(15.1)$ & $57.8(13.6)$ & $58.9(15.8)$ \\
\hline Eating Behaviours & $3.3(1.5)$ & $2.5(1.4)$ & $3.2(1.3)$ & $3.0(1.6)$ \\
\hline
\end{tabular}

\begin{tabular}{|c|c|c|}
\hline \multicolumn{3}{|c|}{ ) } \\
\hline $\begin{array}{l}\text { Primary outcomes: carer } \\
\text { Total HADS }(n=149 \text {, obs. }=377)\end{array}$ & $-3.1(-4.5$ to -1.7$)$ & $<0.001 * *$ \\
\hline $\begin{array}{l}\text { Secondary outcomes: carer } \\
\text { FQ }(n=152, \text { obs. }=380) \\
\text { CSE }(n=104, \text { obs. }=180) \\
\text { EDSIS }(n=152, \text { obs. }=266) \\
\text { GHQ }(n=150, \text { obs. }=263) \\
\text { Negative ECI }(n=153 \text {, obs. }=268) \\
\text { Positive ECI }(n=268, \text { obs. }=153) \\
\text { AESED }(n=122, \text { obs. }=122)\end{array}$ & $\begin{aligned}-3.0 & (-4.8 \text { to }-1.1) \\
9.0 & (4.6 \text { to } 13.5) \\
-4.5 & (-7.4 \text { to }-1.7) \\
-2.7 & (-4.2 \text { to }-1.1) \\
-13.4 & (-19.4 \text { to }-7.5) \\
1.2 & (-0.4 \text { to } 2.8) \\
-9.1 & (-13.4 \text { to }-4.8)\end{aligned}$ & $\begin{aligned} & 0.002^{*} \\
&< 0.001^{* *} \\
& 0.002^{*} \\
& 0.001^{* *} \\
&<0.001^{* *} \\
& 0.1 \\
&<0.001^{* *}\end{aligned}$ \\
\hline $\begin{array}{l}\text { Secondary outcomes: individual with } \\
\text { eating disorder (carer report) } \\
\text { GEDF }(n=146 \text {, obs. }=367) \\
\text { EatBeh }(n=152, \text { obs. }=268)\end{array}$ & $\begin{array}{l}3.5(0.5 \text { to } 6.5) \\
-0.8(-1.2 \text { to }-0.5)\end{array}$ & $\begin{array}{l}0.02^{*} \\
<0.001^{* *}\end{array}$ \\
\hline $\begin{array}{l}\text { ECHO, Expert Carers Helping Others self-he } \\
\text { and Depression Scale; GEDF, Global Eating } \\
\text { Eating Behaviours (indirect); FQ, Family Qu } \\
\text { EDSIS, Eating Disorder Symptom Impact SC } \\
\text { ECI, Experience of Caregiving Inventory; A } \\
\text { Scale for Eating Disorders; obs., observatio } \\
{ }^{*} P<0.05 \text {, }{ }^{* * P}<0.001 \text {. }\end{array}$ & $\begin{array}{l}\text { Ip intervention; HADS, Hospita } \\
\text { Disorder Functioning (indirect) } \\
\text { stionnaire; CSE, Caregiver Sel } \\
\text { le; GHQ, General Health Ques } \\
\text { SED, Accommodation and Ena } \\
\text { IS. }\end{array}$ & $\begin{array}{l}\text { Anxiety } \\
\text {; EatBeh, } \\
\text { f-Efficacy; } \\
\text { stionnaire; } \\
\text { abling }\end{array}$ \\
\hline
\end{tabular}

( $r=-0.5, P<0.0001)$ all correlated with changes in carers' HADS, suggesting that they are all partly mediating the effect on HADS.

Contact time as a mediator of intervention effect on carer behaviour and distress

We explored whether the amount of face-to-face contact and other contact (e.g. telephone) mediated the effect of ECHO on outcomes HADS, FQ and AESED. Carers were split according to whether they had a high ( $>21 \mathrm{~h}$ a week) or low ( $<21 \mathrm{~h}$ per week) level of contact with the patient. Since there was no significant relationship between amount of contact and the effect of the intervention, assumptions for a mediation model were not met; contact time does not appear to mediate the effect of ECHO on carers' HADS, FQ or AESED.

Mediating role of maintaining factors on patient improvement (carer report)

A similar modelling approach was used with GEDF and EatBeh scores as the outcome. The intervention reduced FQ, AESED

\begin{tabular}{|c|c|c|}
\hline & $\begin{array}{c}\mathrm{ECHO}(n=52) \\
\text { mean (s.d.) }\end{array}$ & $\begin{array}{l}\mathrm{ECHOC}(n=47) \\
\text { mean (s.d.) }\end{array}$ \\
\hline Proportion of materials watched/read & $8.13(2.51)$ & $9.21(1.63)$ \\
\hline Usefulness of the information & $8.00(2.25)$ & $8.74(1.64)$ \\
\hline Difficulty of using DVDS & $3.56(3.05)$ & $2.81(2.54)$ \\
\hline $\begin{array}{l}\text { Usefulness of DVD information } \\
\text { for caregiving }\end{array}$ & $7.54(2.16)$ & $7.93(2.16)$ \\
\hline Helpful for stress levels/self-care & $7.04(2.03)$ & $6.94(2.56)$ \\
\hline Helpful for communication & $7.63(1.99)$ & $8.45(1.77)$ \\
\hline Expectations met & $6.34(2.36)$ & $6.73(2.11)$ \\
\hline
\end{tabular}

and EatBeh and increased GEDF scores. We looked at mixed effects models including the mediating variable as a covariate, and the estimated intervention effect lost significance on addition of the mediating variable.

Negative correlations between change scores for FQ $(r=-0.3$, $P<0.001)$ and AESED $(r=-0.4, P<0.001)$ were found with GEDF scores. This finding suggests that changes in these elements partly mediate the effect of the intervention on GEDF scores. In contrast, correlations between FQ change scores and EatBeh scores $(r=0.2, P=0.10)$ and AESED change scores and EatBeh scores $(r=0.2, P=0.09)$ were not significantly different from zero, suggesting that there is no mediating effect on this variable.

\section{Exploratory moderation analyses of ECHO intervention}

We examined whether carers' FQ, AESED and CSE scores and aspects of the caregiving experience (illness duration and living together) measured at pre-intervention moderated the intervention effect on carers' HADS scores. We extended the linear mixed model to contain a main effect of the hypothesised moderating variable at pre-intervention, an interaction of intervention (i.e. time) and moderator variable, and an interaction of coaching and the moderator variable. Significant moderating effects for the standard intervention were obtained for FQ (estimate $-0.2, \quad P=0.04$ ) and AESED (estimate -0.1, $P<0.001)$. The interaction effect for CSE was narrowly not 
significant at the 0.05 threshold. There were no significant moderating effects of coaching.

In order to gain a better understanding of these results, we looked at the effects of the intervention on high, medium and low levels of the moderator variable. There was a greater decrease in HADS following the intervention in those with high baseline levels of FQ (high FQ $=70$ : estimated reduction -6.00 , 95\% CI -9.14 to -2.86 ) in comparison with other groupings (low $\mathrm{FQ}=40$ : estimated reduction $-1.32,95 \% \mathrm{CI}-3.58$ to 0.95 ; medium $\mathrm{FQ}=55$, estimated reduction $-3.66,95 \% \mathrm{CI}-5.21$ to $-2.11)$.

Similarly, ECHO was most effective for people with high levels of AESED (high AESED = 90: estimated reduction - 7.76, 95\% CI -11.01 to -4.52 ; medium $\mathrm{AESED}=60$ : estimated reduction, $-4.32,95 \%$ CI -6.11 to -2.53 ; low $\mathrm{AESED}=30$ : estimated reduction $-0.88,95 \% \mathrm{CI}-2.90$ to 1 ).

The HADS score was reduced for every level of CSE at postintervention and this reduction was greatest for people with low CSE (low CSE $=20$ : estimated reduction $-7.06,95 \%$ CI -10.77 to -3.34 ; medium $\mathrm{CSE}=50$ : estimated reduction $-4.76,95 \%$ CI -6.73 to -2.79 ; high $\mathrm{CSE}=80$ : estimated reduction -2.47 , $95 \%$ CI -4.65 to -0.28$)$.

We also assessed intervention adherence as a moderator. Using the variable illustrating the proportion of DVDs watched, a significant moderating effect was found on the intervention effect for FQ (estimate $-0.7, P<0.03$ ) and AESED (estimate -1.8 , $P=0.02$ ).

The reduction of FQ post-intervention was greatest for people who watched a greater proportion of DVDs (low amount of DVDs watched $=2$ : estimated reduction $1.03,95 \% \mathrm{CI}-2.29$ to 4.35 ; most DVDs $=4$ : estimated reduction $-1.86,95 \% \mathrm{CI}-3.54$ to -0.19 ; all DVDs $=5$ : estimated reduction $-3.31,95 \%$ CI -5.36 to -1.30 ).

The reduction of AESED post-intervention was smallest for people who watched fewer of the DVDs (low amount of DVDs watched $=2$ : estimated reduction $0.79,95 \% \mathrm{CI}-6.87$ to 8.45 ; most DVDs $=4$ : estimated reduction $-6.23,95 \%$ CI -10.07 to -2.39 ; all DVDs $=5$ : estimated reduction -9.75 , 95\% CI -14.44 to -5.05$)$.

We assessed face-to-face contact and other contact as moderators, but found no moderating effect of level of face-toface or other contact between carer and the person they care for on the treatment effect for HADS, AESED or FQ. No significant interaction effects, and thus no significant moderator effects, were found in models that included length of illness or living together as moderators.

\section{Discussion}

This study represents an early phase of the Medical Research Council's framework for complex interventions. ${ }^{1}$ The aims of this exploratory study were to test the interpersonal maintenance model and examine whether telephone guidance improves the effectiveness of a self-help intervention (ECHO) in order to refine its delivery. ${ }^{27}$ Carer distress and almost all secondary outcomes derived from the model improved at post-intervention. Carers also reported improvements in their loved one's level of functioning and eating disorder symptoms. The addition of telephone coaching had no objective additional benefits to the self-help-only intervention, although this group rated some of the acceptability measures more positively.

As predicted by the model, exploratory analyses showed that changes in caregiving self-efficacy, expressed emotion and accommodation and enabling behaviours mediated improvements in carer distress and perceived level of functioning of the individual with the eating disorder. The impact of ECHO was greatest in those carers with the highest levels of expressed emotion and accommodation and enabling behaviours and lowest self-efficacy. Carers who watched a greater proportion of the DVDs exhibited a greater reduction in expressed emotion and accommodating and enabling behaviours.

The results provide preliminary empirical support for the cognitive interpersonal maintenance model of eating disorders. These results suggest that better implementation of the interventions (encouraging carers to watch the DVDs, perhaps by improving their quality) may be of benefit.

The improvement in carers' status is consistent with previous research using different forms of the intervention but with similar content ${ }^{13,14,28}$ and other interventions based on carers' needs. ${ }^{29,30}$ A secondary beneficial effect on patients with eating disorders has also been reported elsewhere. ${ }^{30,31}$

The failure to find an enhanced effect of telephone coaching was unexpected. It is possible that results may be due to lack of power, insufficient sessions or the participation of only one carer in the coaching process. Interestingly, carers who received ECHOc reported less improvement in functioning in the individual they cared for than those in the ECHO group. This may reflect carers' enhanced ability to recognise the symptoms of an eating disorder, or improved communication between carer and their loved one.

\section{Limitations}

No separate comparison group was included in this study and therefore it is possible that some changes in carer outcome are the result of other latent variables such as clinical improvement in the patients or receipt of external support (e.g. family therapy). We visually inspected the data and performed $t$-tests for significant changes during the waiting period. For the outcomes carer distress, self-efficacy, expressed emotion, accommodation and enabling, and positive caregiving burden, we did not find evidence that our assumptions do not hold. However, there are significant changes over the waiting period for caregiving burden, general well-being, and carer-reported variables of the individual with the eating disorder. This suggests that for these outcomes part of the estimated effects during the intervention period might be due to unobserved influences. Carers may have experienced a positive expectation of change and relief at the prospect of receiving support, thus rating their sense of burden and their loved one's state as less severe.

We do not have direct, validated measures from patients. The scaling of the measures used may be problematic, as it is difficult for carers to judge their loved one's level of functioning relative to others. Nevertheless, we were interested in individual change scores and the scaling rules for the instrument were well defined and gave carers a good indication of what symptoms, behaviours and level of impairment would be present at each point on the continuum. Also, carers have important insights into the level of symptomatology and functionality that are not necessarily observed in clinical settings. This study suggests that further research with objective patient measures is of interest.

The study was powered for the primary hypothesis, which was to detect change in carers' distress at post-intervention. Sample size may, therefore, not have been sufficient to detect additional effects of coaching. Our study was not powered to test all potential mediator and moderator effects (e.g. the extent to which patients/ carers were accessing support, the relationship of carer to the individual, the specific symptom profile of the individual with an eating disorder). Although ECHO is designed to be used by all carers, it would be useful for future research to assess the utility 
of ECHO across different carer groups (e.g. fathers, partners). We believe that these would make interesting topics in further research including more complex forms of statistical modelling.

Finally, coaching was conducted by three different coaches. We were, however, unable to include this information in the already complex model. Coach effects should be evaluated in future studies and motivational interviewing adherence should be measured.

\section{Implications}

These results provide empirical support for the cognitive interpersonal model. ${ }^{3,6}$ This skills training package is a low-cost intervention and an easily disseminated resource but the acceptability could be improved by making the materials more attractive and salient. The modified intervention could be used in a fully powered Phase III trial, with direct measurements of eating disorder psychopathology and compared with a no treatment control group. ${ }^{1}$

\footnotetext{
Elizabeth Goddard, MSc, Pamela Macdonald, MSC, Ana Rosa Sepulveda, PhD, Department of Psychological Medicine; Ulrike Naumann, MSc, Sabine Landau, PhD, Department of Biostatistics and Computing; Ulrike Schmidt, MRCPsych, Dr med, PhD, Department of Psychological Medicine; Janet Treasure, PhD, FRCP, Dr med, PhD, Department of Psychological Medicine; Janet Treasure, PhD, FRCP,
FRCPsych, Department of Academic Psychiatry, Institute of Psychiatry, King's College FRCPsych, DePan, UK

Correspondence: Elizabeth Goddard, Department of Psychological Medicine, 5th Floor Bermondsey Wing, Guy's Hospital, London SE1 9RT, UK. Email: Elizabeth.Goddard@kcl.ac.uk

First received 15 Oct 2010, final revision 30 Nov 2010, accepted 23 Feb 2011
}

\section{Funding}

This work presents independent research commissioned by the National Institute for Health Research (NIHR) under Programme Grant for Applied Research (Reference number RP-PG-0606-1043). This work was also supported by the NIHR Biomedical Research Centre for Mental Health, South London and Maudsley NHS Foundation Trust, Institute of Socia Psychiatry and Institute of Psychiatry, King's College London. The views expressed in this publication are those of the authors and not necessarily those of the NHS, the NIHR or the Department of Health.

\section{Acknowledgements}

Thank you to Gill Todd, Jeff Barrera, María Zabala, Idan Naor and Kimberley Davis for their help over the course of the project, and Jane Morris for her creative input. We would like to also thank the family members that have taken part in the study.

\section{References}

1 Campbell $M$, Fitzpatrick $R$, Haines $A$, Kinmonth $A L$, Sandercock $P$, Spiegelhalter $D$, et al. Framework for design and evaluation of complex interventions to improve health. BMJ 2000; 321: 694-6.

2 Michie S, Prestwich A. Are interventions theory-based? Development of a theory coding scheme. Health Psychol 2010; 29: 1-8.

3 Schmidt $U$, Treasure J. Anorexia nervosa: valued and visible. A cognitiveinterpersonal maintenance model and its implications for research and practice. Br J Clin Psychol 2006; 45: 343-66.

4 Hooley JM. Expressed emotion and relapse of psychopathology. Annu Rev Clin Psychol 2007; 3: 329-52.

5 Sepulveda AR, Kyriacou O, Treasure J. Development and validation of the Accommodation and Enabling Scale for Eating Disorders (AESED) for caregivers in eating disorders. BMC Health Serv Res 2009; 9: 171-83.

6 Treasure J, Sepulveda AR, Macdonald P, Whitaker W, Lopez C, Zabala M, et al. The assessment of the family of people with eating disorders. Eur Eat Disord Rev 2008; 16: 247-55.
7 Winn S, Perkins SJ, Murray J, Murphy R, Schmidt U. A qualitative study of the experience of caring for a person with bulimia nervosa. Part 2: Carers' needs and experiences of services and other support. Int J Eat Disord 2004; 36: 269-79.

8 Graap H, Bleich S, Herbst F, Trostmann Y, Wancata J. The needs of carers of patients with anorexia and bulimia nervosa. Eur Eat Disord Rev 2008; 16 21-9.

9 Haigh R, Treasure J. Investigating the needs of carers in the area of eating disorders: development of the Carer's Needs Assessment Measure (CaNAM). Eur Eat Disord Rev 2003; 11: 125-41.

10 Kyriacou O, Treasure J, Schmidt U. Understanding how parents cope with living with someone with anorexia nervosa: modelling the factors that are associated with carer distress. Int J Eat Disord 2008; 41: 233-42.

11 Zabala M, Macdonald $\mathrm{P}$, Treasure J. Appraisal of caregiving burden, expressed emotion and psychological distress in families of people with eating disorders: a systematic review. Eur Eat Disord Rev 2009; 17: 338-49.

12 Rollnick S, Miller W. What is motivational interviewing? Behav Cogn Psychother 1995; 23: 325-34.

13 Sepulveda AR, Lopez C, Macdonald P, Treasure J. Feasibility and acceptability of DVD and telephone coaching-based skills training for carers of people with an eating disorder. Int J Eat Disord 2008; 41: 318-25.

14 Sepulveda AR, Lopez C, Todd G, Whitaker W, Treasure J. An examination of the impact of 'the Maudsley eating disorder collaborative care skills workshops' on the well-being of carers: a pilot study. Soc Psychiatry Psychiatr Epidemiol 2008; 43: 584-91.

15 Treasure J, Smith G, Crane A. Skills-based Learning for Caring for a Loved One with an Eating Disorder: The New Maudsley Method. Routledge, 2007

16 Michie S, Abraham C, Whittington C, McAteer J, Gupta S. Effective techniques in healthy eating and physical activity interventions: a metaregression. Health Psychol 2009; 28: 690-701.

17 Rollnick S, Kinnersley $P$, Stott N. Methods of helping patients with behaviour change. BMJ 1993; 307: 188-90.

18 Zigmond A, Snaith R. The Hospital Anxiety and Depression Scale. Acta Psychiatr Scand 1983; 67: 361-70.

19 Goldberg DP. General Health Questionnaire (GHQ-12). nferNelson, 1992.

20 Szmukler Gl, Burgess P, Herrmann H, Benson A, Colusa S, Bloch S. Caring for relatives with serious mental illness: the development of the Experience of Caregiving Inventory. Soc Psychiatry Psychiatr Epidemiol 1996; 31: 137-48.

21 Sepulveda AR, Whitney J, Hankins M, Treasure J. Development and validation of an Eating Disorders Symptom Impact Scale (EDSIS) for carers of people with eating disorders. Health Qual Life Outcomes 2008; 6: 28-36.

22 Wiedemann G, Rayki O, Feinstein E, Hahlweg K. The Family Questionnaire: development and validation of a new self-report scale for assessing expressed emotion. Psychiatry Res 2002; 109: 265-79.

23 Steffen AM, McKibbin C, Zeiss AM, Gallagher-Thompson D, Bandura A The revised scale for caregiving self-efficacy: reliability and validity studies. J Gerontol B Psychol Sci Soc Sci 2002; 57B: 74-86.

24 Endicott J, Spitzer RL, Fleiss JL, Cohen J. The global assessment scale. A procedure for measuring overall severity of psychiatric disturbance. Arch Gen Psychiatry 1976; 33: 766-71.

25 Baron RM, Kenny DA. The moderator-mediator variable distinction in social psychological research: conceptual, strategic, and statistical considerations. J Pers Soc Psychol 1986; 51: 1173-82.

26 StataCorp. Stata Statistical Software: Release 10. College Station, TX: StataCorp LP, 2007.

27 Crawford JR, Henry JD, Crombie C, Taylor EP. Normative data for the HADS from a large non-clinical sample. Br J Clin Psychol 2001; 40: 429-34.

28 Glasziou P, Chalmers I, Altman DG, Bastian H, Boutron I, Brice A, et al. Taking healthcare interventions from trial to practice. BMJ 2010; 341: c3853.

29 Sepulveda AR, Todd G, Whitaker W, Grover M, Stahl D, Treasure J. Expressed emotion in relatives of patients with eating disorders following skills training program. Int J Eat Disord 2010; 43: 603-10.

30 Zucker NL, Ferriter C, Best S, Brantley A. Group parent training: a novel approach for the treatment of eating disorders. Eat Disord 2005; 13 : 391-405.

31 Uehara T, Kawashima Y, Goto M, Tasaki SI, Someya T. Psychoeducation for the families of patients with eating disorders and changes in expressed emotion: a preliminary study. Compr Psychiatry 2001; 42: 132-8.

32 Goddard E, Macdonald $\mathrm{P}$, Treasure J. An examination of the impact of the Maudsley Collaborative Care skills training workshops on patients with anorexia nervosa: a qualitative study. Eur Eat Disord Rev 2010; Sep 20 (Epub ahead of print). 